\title{
Analisis Pengendalian Biaya Konstruksi Gedung Asrama Dengan Metode Life Cycle Cost
}

\author{
Rini Pebri Utari*, Abdul Samad \\ Universitas Muhammadiyah Malang \\ Jalan Raya Tlogomas No. 246, Tlogomas, Lowokwaru, Kota Malang, Jawa Timur 651441 \\ *Correspondence email: rinipebriutari@umm.ac.id
}

\begin{abstract}
Abstrak. Bangunan memiliki peranan penting bagi kehidupan manusia sesuai dari fungsinya. Setelah proses pembanguan selesai, bangunan tersebut diharapkan dapat menjalankan fungsinya sesuai dengan umur rencana yang diharapkan. Namun pembangunan dengan kualitas bahan bangunan dibawah standar mengakibatkan bangunan cepat mengalami kerusakan sehingga menyebabkan pemeliharaan yang lebih rutin dan biaya pemeliharaan yang tinggi. Objek dalam penelitian ini adalah Gedung asrema putra Politeknik Bali. Salah satu metode yang tepat dalam mengalisa nilai ekonomis suatu bangunan mulai dari perencananaan, pelaksanaan dan pemeliharaan yaitu dengan menggunakan Metode Life Cycle Cost. Dari hasil penelitian didapatkan empat komponen yang meyusun Life Cycle Cost yaitu biaya awal atau biaya pembangunan sebesar Rp.6.407.566.714 (19\%), biaya operasional Rp 21.911.035.624 (64\%), biaya perawatan dan penggantian Rp 5.622.402.603 (16\%), dan biaya perobohan Rp 213.171.382 (1\%). Dan dari penelitian ini diketahui pula biaya siklus penggantian komponen bangunan berdasarkan peraturan PU no 24. Tahun 2008 sehingga diharapkan Gedung Asrama Putra Politeknik Kelautan dan Perikanan Jembrana Bali ini dapat berdiri selama 50 tahun sesuai usia guna bangunan yang diharapkan.
\end{abstract}

Keyword: Biaya Konstruksi; Life Cycle Cost; Initial cost; Financing Costs; Operational Costs

Abstract. Buildings have an important role for human life according to their functions. After the construction process is complete, the building is expected to carry out its functions according to the expected plan age. However, construction with substandard quality building materials causes the building to experience rapid damage resulting in more routine maintenance and high maintenance costs. The object of this research is the Asrema Gedung Putra Polytechnic Bali. One of the appropriate methods in analyzing the economic value of a building starting from planning, implementation and maintenance is to use the Life Cycle Cost Method. From the research results, it is found that four components make up the Life Cycle Cost, namely the initial cost or development cost of Rp. 6,407,566,714 (19\%), operational costs Rp. 21,911,035,624 (64\%), maintenance and replacement costs Rp. 5,622,402,603 (16\%), and the cost for the destruction of Rp. 213,171,382 (1\%). And from this research it is also known that the cost of the building component replacement cycle is in accordance with the regulation No. PU. 24 of 2008 so it is expected that the Jembrana Bali Marine and Fisheries Polytechnic Male Dormitory Building can stand for 50 years according to the expected building age.

Keywords: Construction Costs; Life Cycle Costs; Initial Costs; Financing Costs; Operational Costs

\section{PENDAHULUAN}

Suatu bagunan memiliki peranan penting bagi kehidupan manusia sesuai dari fungsi bangunan tersebut. Setelah proses pembanguan selesai, bangunan tersebut diharapkan dapat menjalankan fungsinya sesuai dengan umur rencana yang diharapkan. Sering dengan penggunaan bangunan tersebut, nilai ekonomis dan kinerja bangunan pasti akan menurun. Adapun factor yang mempengaruhi umur penggunaan bangunan tersebut adalah perencanaan dari segi material yang tepat, berkualitas, kualitifkasi sumber daya pekerja serta metode pengerjaan yang tepat. Rini (2018) menjelaskan bahwa Proyek konstruksi, memiliki beberapa jenis sumberdaya yaitu material, peralatan, sumber daya manusia, biaya dan waktu. Dimana, untuk mencapai mutu konstruksi yang baik diperlukan suatu sistem manajemen untuk mengatur sumber daya tersebut agar dapat dimanfaatkan secara optimal. Metode Life Cycle Cost (LCC) telah digunakan dalam beberapa penelitian, diantaranya penelitian Wongkar (2016) Metode LCC cukup efektif mengidentifikasi besarnya biaya pemeliharan pada proyek Sekolah St. URSULA Kotamobagu, ditemukan indikasi bahwa pemeliharaan terbesar ada pada biaya pemeliharaan. Selain itu, menurut Kamagi (2013) Kegunaan utama Life Cycle Cost adalah pada waktu evaluasi solusi-solusi alternatif atas problema desain tertentu, sebagai contoh, suatu pilihan mungkin tersedia untuk atap suatu proyek baru. Hal yang perlu ditinjau bukan hanya biaya awal saja, tetapi juga biaya pemeliharaan dan perbaikan, usia rencana, penampilan, dan hal-hal yang mungkin berpengaruh terhadap nilai sebagai akibat dari pilihan yang tersedia. Janitra (2018) mampu menemukan biaya paling efektif dari sistem pendingin ruangan pada gedung dengan menggunakan Metode LCC. Begitu pula halnya dengan Firsani (2012) dengan analisa Life Cycle Cost dapat melihat seberapa besar biaya yang dikeluarkan oleh suatu bangunan berkonsep green building selama periode yang ditetapkan. 
Pada penelitian ini ingin menghitung Life Cycle Cost pada Gedung Asrama Putra Politeknik Bali sehingga nantinya dapat menjadi perhatian owner khususnya pada biaya pengelolaan, perawatan dan penggantian komponen berkala sehingga gedung asrama putra ini dapat mencapai usia guna yang diharapkan.

\section{METODE}

\section{Jenis Penelitian}

Penelitian ini menggunakan Pengumpulan data primer dan data skunder Gambar Teknis dan Arsitektur HSPK dan Spesifikasi Teknik. Pengumpulan data primer dan data skunder menggunakan Analisis Life Cycle Cost

\section{Tahap Penelitian}

Pengumpulan data primer dan data skunder menggunakan Analisis Life Cycle Cost:

1. Breakdown Pekerjaan dan perhitungan Volume pekerjaan

2. Perhitungan RAB atau Biaya Awal (initial cost) Proyek Lanjutan Pembangunan Politeknik Kelautan Dan Perikanan Jembrana-Bali

3. Biaya Langsung, terdiri dari:
a. Biaya Prakonstruksi
b. Biaya Konstruksi
c. Biaya Pengawasan, Pajak, Asuransi

4. Biaya pengguna /Operasional (user cost), terdiri dari:

5. Biaya perbaikan masa depan (future rehabilitation cost)

6. Biaya Penghancuran bangunan saat usia 51 tahun

\section{Objek penelitian}

Adapun yang menjadi Objek penelitian adalah Gedung Asrama Putra Politeknik Bali yang bernilai Progress pekerjaan Gedung asrama Putra telah mencapai $100 \%$ penyelesaian. Gedung asrama putra ini ini terdiri dari dua lantai dengan total luas keseluruhan sebesar $644.75 \mathrm{~m} 2$. Pada lantai 1 terdiri dari Ruang areal serbaguna, R. duduk/belajar, R. Resepsionis, Pantri, Lobby, Toilet, R. Tamu dan R. MEP. Sedangkan pada lantai 2 terdapat kamar tidur berukuran $35 \mathrm{~m} 2$ sebanyak 4 kamar, rang kamar pengasuh, areal wastafel, arel shower, kamar mandi dan areal closet.

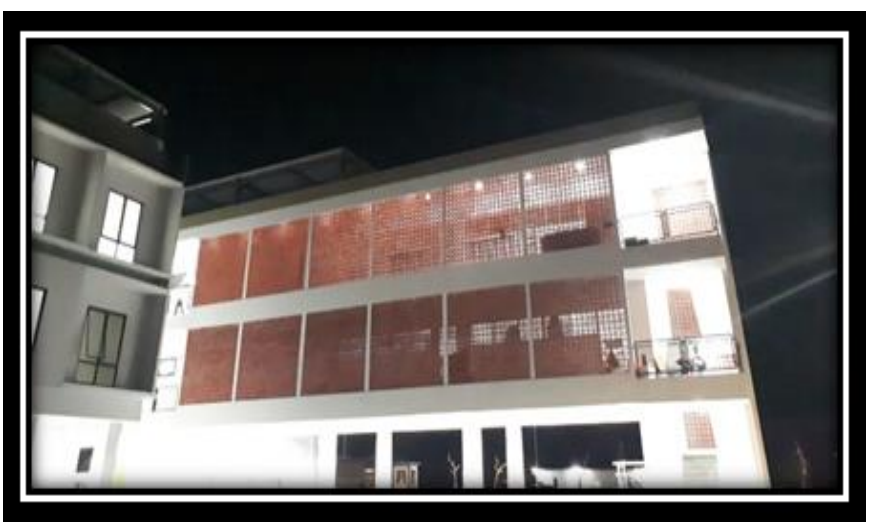

Gambar 1. Tampak Depan Eksisting Gedung Asrama Putra
Dalam penelitian ini secara umum variabel variabel yang akan dihitung untuk mengetahui Life Cycle Cost Pekerjaan Lanjutan Pembangunan Politeknik Kelautan Dan Perikanan Jembrana Bali namun data eksisting proyek akan dipilah menjadi 9 komponen utama dalam Life Cycle Cost, yaitu (1) Initial Costs, (2) Financing Costs, (3) Operational Costs, (4) Maintanance Costs, (5) Replacement Costs, (6) Tax Elements, (7) Associated Costs, (8) Salvage Value

Menurut Heralopa (2019) dalam jurnal Life Cycle Costing Of Public Construction Project, Metode yang digunakan dalam analisis Life Cycle Cost ini adalah nilai masa datang (Future Value) dengan Single Payment Compound Amount Factor (SPCA) dan Equal Payment Series Compound Amount Factor (EPSCA).

Nilai masa datang (future value) merupakan cerminan suatu nilai uang di masa datang dari sejumlah uang yang diinvestasikan saat ini. Dalam analisis single payment compound amount factor akan digunkan untuk perhitungan biaya pemeriksaan (inspection cost), biaya pengguna (user cost) dan biaya perbaikan masa depan (future rehabilitation cost).

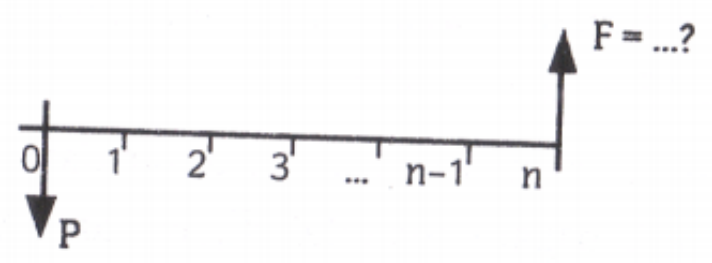

Gambar 2. Single payment (Giatman, 2011)

$F=P(1+i)^{n}$

dimana:

$\mathrm{F}=$ nilai masa datang

$\mathrm{P}=$ nilai sekarang

$\mathrm{n}=$ jumlah periode pembayaran

$\mathrm{i}=$ tingkat suku bunga

Faktor pengali $(\boldsymbol{1}+\boldsymbol{i})^{n}$ di atas disebut faktor pembungaan majemuk tunggal (single payment coumpound amount factor). Faktor bunga tersebut diperoleh melalui tabel bunga. Jika mempergunakan tabel bunga dalam perhitungan ekuivalensi, maka persamaan di atas diubah dengan persamaan faktor bunga menjadi;

$\mathrm{F}=\mathrm{P}(\mathrm{F} / \mathrm{P}, \mathrm{i}, \mathrm{n})$

Dalam analisis equal payment series compound amount factor akan digunkan untuk perhitungan biaya pemeliharaan (maintenance cost) yang dilakukan rutin setiap tahun. Dalam analisis ini di cari nilai F (future) dengan menggunakan nilai A (annual) yang telah ada. 


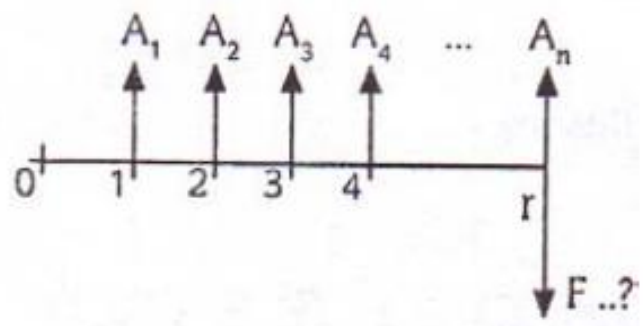

Gambar 3. Annual payment (Giatman, 2011)

\section{HASIL DAN PEMBAHASAN}

\section{Komponen Biaya Life Cycle Cost}

Dalam perencanaan analisis Life Cycle Cost perlu diketahui seluruh rangkaian pengeluaran proyek sepanjang usia proyek tersebut, yaitu mulai dari ide, studi kelayakan, perencanaan, pelaksanaan sampai pada operasi dan pemeliharaan Gedung dengan harapan umur ekonomis bangunan 50 tahun. Adapun pengelompokkan biaya proyek dibagi menjadi beberapa komponen yaitu :
Biaya konstruksi atau biaya modal.

Biaya modal dalam hal ini adalah banyaknya biaya yang telah dikeluarkan dari pra studi hingga proyek ini selesai. Adapun biaya modal ini dibagi menjadi :

\section{Biaya Langsung (Direct Cost)}

Biaya langsung merupakan biaya yang diperlukan dalam proses pembangunan konstruksi ini, yang terdiri dari:

1. Persiapan lahan

2. Biaya Konstuksi

3. Biaya Arsitektural

4. Biaya Instalasi Mekanikal Elektrikal

5. Pekerjaan Plumbing

Adapun biaya langsung Proyek Gedung asrama putra Pembangunan Politeknik Bali, khususnya pada segment Gedung asrama putra dapat dilihat pada tabel 1 .

Tabel 1. Biaya Langsung Gedung Asrama Putra

\begin{tabular}{llcl}
\hline No & \multicolumn{1}{c}{ Jenis Pekerjaan } & Bobot Pekerjaan (\%) & \multicolumn{1}{c}{ Jumlah Harga } \\
\hline 1 & Persiapan lahan & 0,003 & Rp. 55.544.155 \\
2 & Biaya Konstuksi & 0,133 & Rp 2.735.181.596 \\
3 & Biaya Arsitektural & 0,090 & Rp. 1.834.953.438 \\
4 & Biaya Instalasi Mekanikal Elektrikal & 0,012 & RP. 255.439.153 \\
5 & Pekerjaan Plumbing & 0,005 & Rp. 104.718.886 \\
& & & RP. 4.985.837.227 \\
\hline
\end{tabular}

Persentase biaya langsung dapat dilihat pada gambar 4.

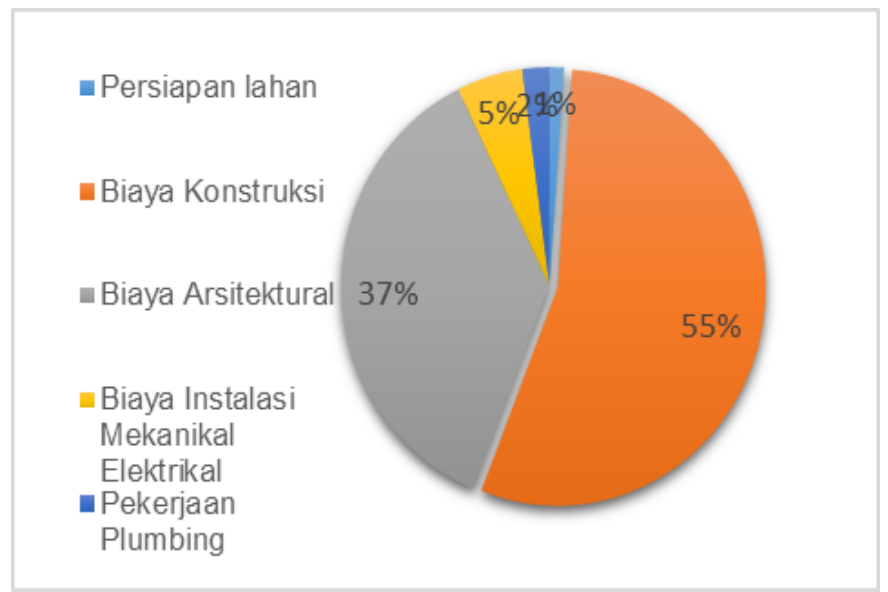

Gambar 4. Presentase Biaya Langsung

\section{Biaya tidak langsung (Indirect Cost)}

Biaya tidak langsung merupakan biaya yang dikeluarkan untuk biaya manajemen, jasa/upah dalam pembangunan proyek konstruksi, yang meliputi :

1. Pajak Bumi dan Bangunan

Adapun nilai PBB Gedung asrama putra ini sebesar Rp. 7.011.684

2. Asuransi

Adapun biaya asuransi Gedung asrama putra sebesar Rp 14.921.997,68.

\section{Biaya Investasi}

Adapun biaya Investasi dari Gedung asrama putra dapat di lihat pada tabel 2 .

Tabel 2. Biaya Investasi

\begin{tabular}{|c|c|c|}
\hline Pekerjaan & & Jumlah Biaya \\
\hline Prakonstruksi & & Rp. 1.315.958,759 \\
\hline UPL\&UKL & & Rp. 25.007.000.,00 \\
\hline Konstruksi & & Rp. $4.985 .837,227$ \\
\hline Pengawasan & & RP. 59.830.046,72 \\
\hline & Total & Rp. 6.386.633.032 \\
\hline
\end{tabular}

\section{Biaya Operasional}

Berdasarkan hasil perhitungan dketahui biaya operasional Gedung terdiri dari

1. Gaji pegawai

Adapun besar gaji pegawai pertahun adalah sebesar Rp. 229.433.600

2. Biaya air dan listrik

Kebutuhan Listrik \& air dalam setahun adalah sebesar Rp.353.216.514,-

3. Biaya Pemeliharaan Gedung

Adapun biaya pemeliharaan Gedung yaitu sebesar $633.75 \mathrm{~m}^{2}$ x Rp. 4.500 .000 x $2 \%=$ Rp. 57.037.500.

\section{Biaya penggantian}

Biaya komponen yang memerlukan penggantian secara berkala sesuai usia ekonomis komponen tersebut. Sebelum menghitung biaya penggantian yang perlu 
dilakukan adalah menentukan komponen-komponen perbaikan dari asrama putra. Dalam penggantian cat Gedung dihitung berdasarkan peraturan Menteri PU No. 24 tahun 2008 tentang Pedoman Pemeliharaan dan Perawatan Bangunan Gedung. Dalam penelitian ini batasan komponen yang dipilih hanya pada pekerjaan arsitektural, dimana bagian ini sering terekspose sehingga akan mempengaruhi tampak keindahan dari bangunan. perencanaan pekerjaan biaya penggantian bertujuan untuk memudahkan pemilik gedung asrama Politeknik Bali dalam memperkirakan biaya masa depan, sehingga dalam pengelolaanya kedepan dapat diperkirakan biaya yang dibutuhkan serta kapan di perlukan penggantian

Adapun biaya penggantian dapat dilihat pada tabel 3.

Tabel 3. Biaya Penggantian Komponen Gedung Asrama Putra Politeknik Bali

\begin{tabular}{|c|c|c|c|c|c|c|}
\hline Pekerjaan & Item & $\begin{array}{c}\text { Usia } \\
\text { Penggantian } \\
\text { (Tahun) }\end{array}$ & Volume & satuan & $\begin{array}{c}\text { Harga Satuan } \\
\text { (Rp) }\end{array}$ & $\begin{array}{l}\text { Harga Total } \\
\text { (Rp) }\end{array}$ \\
\hline \multirow{2}{*}{ Pengecatan } & Dinding & 7 & 2196.95 & $\mathrm{~m} 2$ & $21.600,00$ & $47.454 .120,00$ \\
\hline & Plafon & 6 & 1306.05 & $\mathrm{~m} 2$ & $19.20,00$ & $25.076 .160,00$ \\
\hline \multirow{4}{*}{$\begin{array}{l}\text { Penggantian } \\
\text { Komponen Pintu dan } \\
\text { jendela }\end{array}$} & jendela & 6 & 84 & unit & $393.127,00$ & $33.022 .668,00$ \\
\hline & Daun pintu & 20 & 40 & unit & $995.143,00$ & $39.805 .720,00$ \\
\hline & Kunci Pintu & 20 & 84 & unit & $55.000,00$ & $4.620 .000,00$ \\
\hline & Engsel Pintu & 20 & 168 & unit & $62.000,00$ & $10.416 .000,00$ \\
\hline Plafon & Plafon & 25 & 1306.05 & $\mathrm{~m} 2$ & $54.864,00$ & $71.655 .127,20$ \\
\hline \multirow{2}{*}{ Atap } & Penutup atap zinca & 30 & 1306.05 & $\mathrm{~m} 2$ & $62.247,60$ & 81.298.477,98 \\
\hline & Nok genteng metal & 30 & 362.52 & $\mathrm{~m} 2$ & $99.600 ., 00$ & $36.106 .992,00$ \\
\hline \multirow{2}{*}{ Mekanikal } & Kran air & 20 & 218 & unit & $42.720,00$ & $9.312 .960,00$ \\
\hline & Pompa Air & 15 & 2 & unit & $19.200 .000,00$ & $38.400 .000,00$ \\
\hline \multirow{3}{*}{ Elektrical } & Saklar tunggal & 20 & 115 & unit & $65.880,00$ & $7.576 .200,00$ \\
\hline & Saklar ganda & 20 & 102 & unit & $78.360,00$ & $7.992 .720,00$ \\
\hline & Stop Kontak & 20 & 156 & unit & $50.400,00$ & 7.862 .400 .00 \\
\hline
\end{tabular}

\section{Biaya Perobohan}

Pada penelitian ini biaya perobohan di asumsikan 5\% dari nilai konstruksi. Biaya tersebut termasuk biaya pengolahan limbah sehingga dapat di buang Seperti beton, keramik dan lain-lain, maka biaya perobohan yang di dapatkan sebagai berikut:

Biaya Perobohan $=\mathrm{Rp} 4 \cdot 263.427 .909,72 \times 10 \%=\mathrm{Rp}$ 213.171.392,49

Perobohan dilakukan ketika umur ekonomis bangunan telah selesai yaitu selama 50 tahun, maka perobohan dilakukan pada tahun ke 51 .

\section{Rekapitulasi Biaya Siklus Hidup}

Adapun rekapitulasi biaya siklus hidup gedung asrama putra dan putri Politeknik Kelautan dan Perikanan Jembrana Bali di tampilakan dalam table untuk masa usia guna 50 tahun.

Tabel 4. Tabel Rekapitulasi Biaya Siklus Hidup

\begin{tabular}{lc}
\hline \multicolumn{1}{c}{ Biaya yang terjadi } & Besarnya biaya \\
Biaya Langsung (Prakonstruksi, & Rp.6.408.566.714 \\
Konstruksi, Pengawasan, dll) & \\
Biaya Operasional & Rp.21.91..035.624 \\
Biaya perawatan dan penggantian & Rp.5.622.402.603 \\
Biaya penghancuran & Rp.213.171.392,- \\
\multicolumn{1}{c}{ Total Biaya $L C C$} & Rp.34.155.176.335 \\
\hline
\end{tabular}

Adapun presentase biaya siklus hidup mulai dari perencanaan, pelaksanaan, hingga perawatan sampai usia guna yang diharapkan, di gambarkan dalam bentuk diagram pie pada gambar 6 .

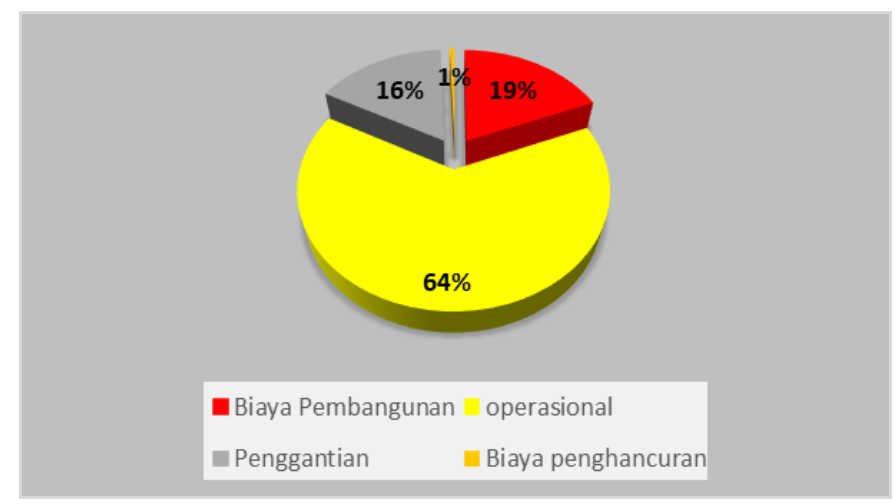

Gambar 5. Diagram presentase biaya siklus hidup

\section{SIMPULAN}

Dari hasil penelitian didapatkan empat komponen yang meyusun Life Cycle Cost yaitu biaya awal atau biaya pembangunan sebesar Rp.6.407.566.714 (19\%), biaya operasional Rp 21.911.035.624 (64\%), biaya perawatan dan penggantian Rp 5.622.402.603 (16\%), dan biaya perobohan Rp 213.171.382 (1\%). Dan dari penelitian ini diketahui pula biaya siklus penggantian komponen bangunan berdasarkan peraturan PU no 24 . Tahun 2008 sehingga diharapkan Gedung Asrama Putra Politeknik Kelautan dan Perikanan Jembrana Bali ini dapat berdiri selama 50 tahun sesuai usia guna bangunan yang diharapkan. 


\section{DAFTAR PUSTAKA}

Heralova, R Schneiderova. 2019. Life Cycle Costing of Public Construction Project. Iop Converence Series : Earth and Environmental Science. Central Europe toward Suistainable Building. doi : 10.1088/1755-1315/290/1/012060

Firsani, Trixsi. \& Utomo, C., 2012. Analisa Life Cycle Cost pada Green Building Diamond Building Malaysia. teknik ITS, 1(September (2012)), pp.D34-D38.

Giatman. (2011) Ekonomi teknik. Jakarta: PT Raja Grafindo Persada Hestin dan Rully.(2011).Pemeliharaan bangunan: basic skill management.Yogyakarta:Andi

Janitra,Kevin.,Widyanugraha,Khrisna.,Alifin,Setiawarda ni. 2018. Perhitungan Life Cycle Cost Sistem Pendingin Ruangan Pada Gedung Hotel Goldvitel Surabaya. Jurnal Dimensi Pratama Teknik Sipil Volume 7, No 1.

Kamagi, Grace Priscillia. 2013. Analisis Life Cycle Cost Pada Pembangunan Gedung (Studi Kasus : Proyek Bangunan Rukan Bahu Mall Manado). Jurnal Sipil Statik Vol.1 No.8, Juli 2013 (549-556) ISSN: 2337-6732549

Kementerian Pekerjaan Umum. (2008). Permen PU No. 24/PRT/M/2008 tentang Peraturan Menteri Pekerjaan Umum dan Perumahan Rakyat tentang Pedoman Pemeliharaan dan Perawatan Bangunan Gedung Jakarta: Kemen PU.

Utari, Rini Pebri. 2018. Permodelan Proporsi SDM, Material Dan Alat Pada Proyek Konstruksi Gedung Sederhana \& Non Sederhana Studi Kasus : Beberapa Proyek Konstruksi Di Wilayah Jawa Timur. Jurnal Hexagon Volume 3 no 12018.

Wongkar, Kristti, Yellih. 2016. Analisis Life Cycle Cost Pada Pembangunan Gedung. Jurnal Sipil Statik Vol.4 No.4 (253-262) ISSN: 2337-6732. 